\title{
Weight Management in Patients with Type 1 Diabetes and Obesity
}

\author{
Adham Mottalib $^{1} \cdot$ Megan Kasetty $^{1,2} \cdot$ Jessica Y. Mar ${ }^{1,3} \cdot$ Taha Elseaidy $^{1}$. \\ Sahar Ashrafzadeh ${ }^{1}$. Osama Hamdy ${ }^{1,4}$
}

Published online: 23 August 2017

(C) The Author(s) 2017. This article is an open access publication

\begin{abstract}
Purpose of review Patients with type 1 diabetes (T1D) are typically viewed as lean individuals. However, recent reports showed that their obesity rate surpassed that of the general population. Patients with T1D who show clinical signs of type 2 diabetes such as obesity and insulin resistance are considered to have "double diabetes." This review explains the mechanisms of weight gain in patients with T1D and how to manage it.

Recent findings Weight management in T1D can be successfully achieved in real-world clinical practice.

Summary Nutrition therapy includes reducing energy intake and providing a structured nutrition plan that is lower in
\end{abstract}

This article is part of the Topical Collection on Obesity

Osama Hamdy

osama.hamdy@joslin.harvard.edu

Adham Mottalib

adham.mottalib@joslin.harvard.edu

Megan Kasetty

megkasetty@gmail.com

Jessica Y. Mar

jessicayumar@gmail.com

Taha Elseaidy

taha.elseaidy@joslin.harvard.edu

Sahar Ashrafzadeh

sahar.ashrafzadeh@joslin.harvard.edu

1 Joslin Diabetes Center, Harvard Medical School, Boston, MA 02215, USA

2 Tufts University School of Medicine, Boston, MA 02111, USA

3 Tufts University, Medford, MA 02155, USA

4 One Joslin Place, Boston, MA 02215, USA carbohydrates and glycemic index and higher in fiber and lean protein. The exercise plan should include combination stretching as well as aerobic and resistance exercises to maintain muscle mass. Dynamic adjustment of insulin doses is necessary during weight management. Addition of antiobesity medications may be considered. If medical weight reduction is not achieved, bariatric surgery may also be considered.

Keywords Type 1 diabetes - Obesity · Weight management . Nutrition therapy $\cdot$ Anti-obesity medications $\cdot$ Bariatric surgery

\section{Introduction}

In the past 20 years, the prevalence of obesity has tripled worldwide, to the extent that it is now being considered an epidemic [1]. Obesity, defined as a body mass index (BMI) of $\geq 30 \mathrm{~kg} / \mathrm{m}^{2}$, affects approximately $35 \%$ of men and $40 \%$ of women in the USA [2••]. It has recently been reported that obesity in particular is rising at a greater rate than overweight [3].

Though patients with type 1 diabetes (T1D) have traditionally been thought to have lower BMI, current research has shown otherwise [4]. The trend of increasing obesity prevalence has increased at a faster rate in patients with T1D compared to the general population [5]. Currently, around 50\% of patients with T1D are either overweight or obese. They also have higher waist and hip circumferences when compared to healthy controls [4]. In the Pittsburgh Epidemiology of Diabetes Complications (EDC) Study, which followed adult patients with T1D for an average of 18 years, prevalence of overweight increased from 29 to $42 \%$ and prevalence of obesity increased sevenfold from 3 to $23 \%$ [5]. Weight gain appeared to be unrelated to aging and instead related to clinical factors such as insulin therapy [5]. 
Comorbidities, often associated with excess body weight, reduce the benefits of good metabolic control [6]. Thus, controlling body weight in patients with T1D is necessary due to the well-known relationship between obesity and cardiovascular disease (CVD) [7••]. Metabolic abnormalities related to obesity, such as the pro-inflammatory state, are likely to modify CVD risk in this population [7••]. So far, complications related to CVD have been the leading cause of mortality in patients with T1D [8]. In this review, we aim to describe the different mechanisms by which patients with T1D gain excess body weight and how clinicians can help them manage it.

\section{Mechanisms of Weight Gain}

\section{Insulin Therapy}

Insulin is anabolic hormone that plays a role in inhibiting protein catabolism, stimulating lipogenesis, and slowing basal metabolism $[4,5,9]$, resulting in increased fat accumulation $[9,10]$. Inhibiting protein catabolism is another anabolic process, in which weight gain may also occur through an increase in lean body mass [11]. These effects are enhanced by exogenous insulin administration [4], since exogenous insulin imperfectly mimics endogenous secretion $[9,12]$. While endogenous insulin has its first pass to the liver through the portal vein to suppress gluconeogenesis [9], exogenous insulin circulates systemically first and disproportionately affects muscle and adipose in comparison to the liver [9].

\section{Intensity of Insulin Therapy}

Intensity of insulin treatment influences weight gain as shown in the Diabetes Control and Complications Trial (DCCT), where patients on intensive insulin therapy gained an average of $4.6 \mathrm{~kg}$ over 5 years, which is significantly more than patients in the study's conventional arm [13]. In that study, participants treated with intensive insulin therapy administered insulin either by multiple daily injections (MDI) or through continuous subcutaneous insulin infusion (CSII) by insulin pumps [13]. Participants on conventional therapy administered one to two daily injections of intermediate and rapidacting insulin, usually with no daily adjustments [13]. Weight gain was observed in the intensive insulin therapy cohort as a whole, regardless of MDI or CSII administration [13]. Similarly, a meta-analysis comparing multiple outcomes in adults with T1D using either MDI or CSII found no difference in weight gain [14]. Despite weight gain, intensive insulin treatment is the standard of care because of its strong clinical benefits such as reduction of glycated hemoglobin ( $\mathrm{HbAlc})$ and reduction of long-term microvascular complications [13]. Part of weight gain in association with intensive insulin therapy in T1D has traditionally been seen as normalization of weight by correcting for glycosuria, diuresis, and catabolism [5]. It was also noted that moderate weight gain did not negatively affect cardiovascular risk profile when associated with improved glycemic control [15]. This furthers the point that weight gain in patients with T1D on intensive insulin therapy is complex and multifaceted, but thus far a healthy balance must be reached.

\section{Type of Insulin Therapy}

Limited research had been conducted on how different types insulin and their methods of administration affect body weight in patients with T1D [16••]. However, multiple trials have shown that patients with T1D who used insulin detemir as the basal component of intensive insulin therapy maintained weight neutrality or even had small weight reductions over 1 year in comparison to NPH insulin $[9,10]$. This could be related to its near-physiologic mechanism by inducing greater suppression of hepatic glucose output [17]. One study also showed that insulin glargine initially caused less weight gain than NPH insulin, but the difference disappeared after 1 year [10]. Weight gain may also be modified by insulin concentration. Two clinical trials comparing insulin glargine U300 to insulin glargine U100 in patients with T1D reported less weight gain over 6 months with insulin glargine U300, yet insulin requirements increased $[16 \bullet \bullet]$.

\section{Growth Hormone and Insulin-like Growth Factor-1}

The non-physiological mechanism of exogenous insulin administration negatively affects growth hormone $(\mathrm{GH})$ and insulin-like growth factor (IGF)-1, which help in maintaining the delicate balance between catabolism and anabolism [9]. Normally, GH regulates IGF-1 and counteracts insulin action by promoting lipolysis and inhibiting insulin-induced suppression of hepatic gluconeogenesis [12]. Higher concentration of GH blocks insulin signaling, resulting in elevation of both blood glucose and insulin concentrations [12]. Since patients with T1D are insulin deficient, hepatic IGF-1 synthesis is impaired resulting in decreased feedback suppression of GH and increases in GH concentration [12].

\section{Double Diabetes}

Double diabetes is a new term used to describe patients with T1D who also show clinical signs of type 2 diabetes (T2D) such as obesity and insulin resistance (IR) $[12,16 \bullet \bullet]$. With the rising rates of overweight and obesity among patients with T1D, there are no longer clear divisions between the two major diabetes subtypes except at time of diagnosis, as the disease appears to behave as a continuum with the two components of its etiology, insulin deficiency, and IR [12]. Double diabetes tends to occur when the proinflammatory state associated with metabolic syndrome leads to 
reduced glycemic control, eventually requiring higher daily doses of insulin [18•]. Increasing insulin dosage due to IR can lead to further weight gain, thus exacerbating the weight problem [18•]. Patients with T1D who are overweight or obese are at a greater risk of developing double diabetes due to their significantly elevated levels of osteopontin (OPN) [19]. OPN is a sialoprotein associated with normal physiological processes as well as autoimmune disease and has been demonstrated to induce adipose tissue inflammation, increase pro-inflammatory cytokine release, and promote development of IR [20]. Fortunately, weight loss reduces circulating OPN concentrations [19]. Double diabetes is a cyclical mechanism of weight gain and IR that should be recognized and treated early.

\section{Physical Inactivity}

Increased physical activity to enhance weight loss is widely accepted, but adults with T1D tend to partake in less physical activity than adults without diabetes [21]. The main barrier to physical activity reported is fear of severe hypoglycemia [21]. Though this is a clear psychological barrier, it is also a valid concern since hypoglycemia is the most common adverse event of physical activity in patients with T1D [22]. Hypoglycemia may occur during or up to $24 \mathrm{~h}$ after activity [22]. To prevent hypoglycemia, patients usually reduce their insulin dose before exercise, but this strategy can only be used when exercise is planned in advance [23]. An additional drawback is that patients try to keep their blood glucose higher before exercise in order to maintain proper glycemic profile during and after exercise [23]. They do that by increasing consumption of carbohydrates before and during exercise, which results in increased energy intake and consequent weight gain [23].

\section{Weight Management in Type 1 Diabetes}

\section{Nutrition Therapy}

The American Diabetes Association recommends weight loss for all overweight or obese individuals with diabetes or at risk for diabetes [24]. Many nutrition-based approaches for weight loss have been studied in individuals with or without diabetes, but very few studies were specific to patients with T1D. For patients with $\mathrm{T} 2 \mathrm{D}$, certain macronutrient compositions such as low-carbohydrate or low-fat calorie-restricted diets and different eating patterns including Mediterranean and vegetarian dietary plans were shown to be successful for up to 2 years [24]. In a 2-year study comparing low-carbohydrate, low-fat, and Mediterranean dietary plans in obese participants, mean weight loss was $2.9 \mathrm{~kg}$ in the low-fat group, $4.4 \mathrm{~kg}$ in the Mediterranean diet group, and $4.7 \mathrm{~kg}$ in the lowcarbohydrate group [25]. Among the 36 participants with
T2D in the study, the Mediterranean diet, which is rich in vegetables and healthy fats and low in red meat, was the most favorable for changes in fasting plasma glucose and insulin levels [25]. The low-carbohydrate diet resulted in the greatest $\mathrm{HbA} 1 \mathrm{c}$ reduction of $0.9 \%$ over 2 years [25]. Plant-based vegetarian or vegan diets [26] and the Dietary Approaches to Stop Hypertension (DASH) diet [27] have also been shown to induce weight loss and modest improvements in diabetes management. The low-fat vegan diet, devoid of all animal products, was associated not only with sustained weight reduction but also with reductions in total cholesterol and LDLcholesterol in comparison to a cohort following the American Diabetes Association guidelines [26]. In a similar study, participants on a vegan diet had a decrease in $\mathrm{HbAlc}$, attributed to loss of visceral fat [28]. Less restrictive vegetarian diets also promoted weight loss and reduced HbAlc [29]. The DASH diet, emphasizing vegetables, fruit, low-fat dairy, nuts, seeds, and whole grains while limiting meat, poultry, eggs, and oils, has shown beneficial effects on body weight, total and LDL-cholesterol, and insulin sensitivity [30].

Although these dietary plans, with different macronutrient compositions, have been shown to induce significant weight loss, the American Diabetes Association has determined in its position statement that there is no ideal macronutrient composition for meal plans. Current recommendations state that patients with diabetes should work with nutritionists to develop individualized eating plans based on the patient's metabolic status, life circumstances, and food preferences [24].

Regardless of macronutrient breakdown, total energy intake must be appropriate to the weight management goal [24]. However, there are distinctions to be made in the quality of macronutrients and how they affect CVD risk factors and glycemic parameters [31•]. For carbohydrate consumption, intake of dietary fiber has been inversely associated with allcause mortality in diabetes, while high glycemic load and sugar intake were associated with increased mortality [32]. In patients with T1D, meals with the same carbohydrate content but different glycemic indices produced significant differences in postprandial blood glucose, with low GI meals producing a $20 \%$ lower glycemic response than high GI meals [33]. For protein consumption, diets containing leaner sources of protein such as chicken and soy result in more favorable lipid profiles than diets containing red meat [34]. For fat consumption, type and source of fat are more important than the percentage or total amount of fat [35]. Diets containing foods high in monounsaturated fatty acids, such as extra-virgin olive oil and nuts, decreased CVD risk [36] and should therefore replace saturated and trans fatty acids [35].

\section{Increased Physical Activity and Exercise}

Although weight loss can be achieved with only restriction of energy intake, increasing physical activity and incorporating 
exercise training into a weight loss plan lead to greater loss of fat mass and preservation of lean muscle mass compared to energy restriction alone [37, 38]. Additionally, there are metabolic benefits to partaking in physical activity for weight loss [37]. In patients with T1D, physical activity has been shown to decrease cardiovascular risk and mortality [39], in addition to improving lipid profile and endothelial function [40]. In patients with T2D, physical activity improves insulin sensitivity $[39,41]$. As explained earlier, IR is not unique to those with T2D, as patients with T1D tend to be more insulin resistant than their counterparts without diabetes [39]. Therefore, the benefits of exercise on insulin sensitivity are pertinent to this population, especially in those who are overweight or obese.

Highly variable data exists as to what type of physical activity is best suited for weight reduction. Resistance training alone is associated with fat loss but has minimal effect on overall weight loss [42]. Even when resistance therapy is combined with aerobic training, this seems to lead to a similar amount of weight loss as aerobic training alone [37, 42]. One study showed that aerobic exercise was shown to lower visceral adipose tissue to a greater extent than progressive resistance training when compared to control groups [43]. However, the major benefit of resistance exercise is to preserve lean muscle mass during weight loss [44]. This is especially important since patients with diabetes have progressive lean muscle loss as they age [45].

In terms of exercise intensity, some studies have shown that high intensity interval training (HIIT), consisting of repeated bursts of rigorous exercise immediately followed by low intensity recovery, can lead to significant reductions in abdominal fat [46-48]. However, other evidence showed that while this approach is time efficient, it is no more effective than continuous moderate aerobic exercise in promoting fat loss [49]. This supports the observation that rigorous and moderate intensity aerobic training results in similar amounts of weight loss when intensities of physical activity are matched in energy expenditure [42]. Patients can partake in the type of physical activity they find most suitable as long as their energy expenditure is in line with their weight loss goals. Risk of hypoglycemia during or after exercise can be minimized if blood glucose is closely monitored before, during, and after exercise, and individual adjustments in insulin or food intake are made [50]. Patients with T1D should be safely able to participate in aerobic or weight-based physical activities if appropriate pre-exercise measures are taken $[51 \bullet \bullet]$.

\section{Medications}

\section{Insulin}

Adjustment of insulin treatment to facilitate weight reduction has been suggested [52]. Long-acting insulin creates a pattern of 24-h hyperinsulinemia, which stimulates lipogenesis and inhibits lipolysis [52]. Long-acting insulin such as NPH and glargine induce weight gain in patients with T1D [53]. If longacting insulin is indicated, insulin detemir, insulin degludec, and insulin glargine U300 are preferred as they cause less weight gain compared to NPH or insulin glargine U100 [54-57]. To minimize the hypoglycemic risk and the unnecessary consumption of extra-calories, it is better to administer short-acting insulin immediately after meals or within $20 \mathrm{~min}$ from the start of the meal [58]. This gives patients the ability to calculate the short-acting insulin dosage based on the food that they actually consumed and not on what they presumed to eat. In patients with $\mathrm{T} 1 \mathrm{D}$, insulin glulisine is preferred in such scenarios due to its faster onset of action [58].

\section{Metformin}

Metformin is a potent anti-hyperglycemic agent used to treat T2D; however, several studies used metformin alongside intensive insulin therapy to treat patients with T1D and obesity $[59,60]$. In a recent randomized control trial, patients with T1D using metformin had significant improvements in body weight and lipid profile over 3 years [61••]. While there was an initial reduction in $\mathrm{HbA} 1 \mathrm{c}$ over the first 3 months of using metformin, this improvement was not maintained for over the next 33 months [61••]. However, these patients had a significant reduction in insulin dose requirements which is explained by metformin's action as an insulin sensitizer [61••]. So far, US Food and Drug Administration (FDA) has not approved metformin for use in patients with TID.

\section{Glucagon-like Peptide-1 (GLP-1) Analogs}

GLP-1 is an incretin hormone that is involved in both peripheral and central pathways mediating satiation [62]. GLP-1 analogs are currently used to treat T2D and obesity. They reduce appetite and slow gastric emptying and thus reduce body weight and body fat by lowering energy intake [63]. Their use in patients with T1D resulted in significant weight reductions in overweight and obese patients [64••]. However, improvement in glycemic control did not reach statistical significance in trials using active comparators [64••]. Liraglutide, a GLP-1 analog, in conjunction with insulin has been shown to improve glycemic control and induce weight loss in patients with T1D $[65,66]$. It was also found to reduce insulin dose [67]. While it is not approved for patients with T1D, its higher doses ( 2.4 and $3 \mathrm{mg}$ /day) can be used to treat obesity. In a crossover study, exenatide treatment reduced postprandial plasma glucose but did not change HbAlc in patients with T1D $[66,68]$. Another study showed that adding once weekly exenatide to insulin therapy significantly improved $\mathrm{HbAlc}$, body weight, BMI, and reduced insulin doses [69, 70]. Currently, exenatide is not FDA-approved for use in patients with T1D. 


\section{Amylin Analog}

Pramlintide is an injectable, synthetic form of human amylin [71]. Amylin is a beta cell hormone co-secreted with insulin and is nearly absent in patients with T1D [72•]. Amylin regulates blood glucose by slowing gastric emptying, suppressing glucagon secretion, and suppressing appetite to decrease food intake [72•]. Injecting pramlintide before meals in patients with T1D improves $\mathrm{HbAlc}$, decreases postprandial blood glucose level, reduces insulin need, and induces weight loss [72•].

\section{Sodium-Glucose Transporter-2 (SGLT-2) Inhibitors}

This new class of medications reduces blood glucose by inhibiting glucose reabsorption in the proximal convoluted tubules of the nephrons [73]. Excretion of glucose in urine reduces body weight in addition to reducing HbAlc [74]. Recent studies showed cardiovascular benefits of two medications from this class; empagliflozin and canagliflozin [75, 76]. Several studies were done in patients with T1D showing reduction in plasma glucose and body weight but with increased incidence of ketoacidosis [77, 78]. Currently, this drug class is only FDA-approved for use in patients with T2D. Dual SGLT-1 and SGLT-2, sotagliflozin, is being investigated for use in patients with T1D [79•].

\section{Anti-obesity Medications}

There are four new anti-obesity medications approved recently by the US FDA (lorcaserine, topirmate/phentermine, neltroxone/bupropion, liraglutide). All of them plus the older medications like Orlistat and Phentermine are effective for weight loss with variable efficacy and side event profiles [80]. No studies using these medications were specifically conducted in patients with T1D. However, these medications showed reduction in $\mathrm{HbAlc}$ and number or doses of diabetes medications in patients with T2D [81-83]. It is not clear if this effect is related to weight loss or it is specific to the mechanisms of action of these medications.

\section{Bariatric Surgery}

There are several surgical options to reduce body weight that are constantly suggested for patients with T2D [84]. The most commonly used methods are laparoscopic adjustable gastric banding (LAGB), sleeve gastrectomy (SG), and Roux-en-Y gastric bypass (RYGB) [84-88]. All of these methods were shown to significantly reduce body weight with variable duration [89-91] and improve glycemic control and may induce partial or complete remission from T2D, especially when they are done early in the course of the disease [92]. Several case series have been reported in obese patients with T1D showing reductions in body weight and insulin doses as well as a modest reduction in $\mathrm{HbAlc}$ [93••].

\section{Roux-en-Y Gastric Bypass}

This procedure reduces stomach size by creating a small 1530-mL gastric pouch [94]. While the mechanisms by which it improves blood glucose are only partially understood, there is good understanding of how it enables weight loss [94]. This surgery alters different gut hormone responses including GLP1 and ghrelin, a potent hunger hormone [94]. After gastric bypass operations, GLP-1 secretion in response is significantly increased and this is presumed to contribute to the observed improvement in glycemic control [95-98]. It has been suggested that this surgery does not have a similar benefit on glycemic control if residual beta cell function is absent $[99,100]$.

A study comparing different types of bariatric surgeries found that complications are more likely to occur with RYGB than with sleeve gastrectomy [101]. Another study suggests that many patients who initially have remission from T2D relapse at some point after these procedures, particularly with RYGB and biliopancreatic diversion [87]. There is also a recognized risk of postprandial hypoglycemia [102] and weight regain after this procedure [103].

Sleeve Gastrectomy Sleeve gastrectomy restricts stomach size by removing stomach fundus that contains cells that secrete ghrelin hormone. This results in a significant reduction in food intake and suppression of appetite [102, 104]. Now, it is the most commonly prescribed bariatric surgery due to its efficacy and durability in treating obesity and associated comorbidities [105]. Sleeve gastrectomy is associated with similar rates of complications as gastric RYGB [106].

A study that compared the effects of bariatric surgery in patients with T2D and T1D diabetes found that surgery could benefit T1D patients in terms of weight loss and improved glycemic control [107]. It was noted that after 1 year, the decrease in median HbA1c in patients with T1D was much less than in those with T2D [107]. In contrast, a few studies suggest that improved glycemic control may not be a probable outcome of bariatric surgery $[108,109]$.

\section{Conclusion}

Prevalence of obesity has increased at faster rate in patients with T1D than in the general population. While intensive insulin therapy, lack of physical activity, and development of double diabetes explain some of the mechanisms for weight gain in patients with T1D, little is studied about effective interventions for weight management in this population who were portrayed for long as being lean. Dietary intervention, increased physical activity and exercise, adjustment of insulin therapy, adding other diabetes 
medications that positively impact body weight, or adding antiobesity medications are suggested. If medical weight management fails, bariatric surgeries are valid methods for weight management in patients with T1D.

\section{Compliance with Ethical Standards}

Conflict of Interest Adham Mottalib, Megan Kasetty, Jessica Y. Mar, Taha Elseaidy, and Sahar Ashrafzadeh declare that they have no conflict of interest.

Osama Hamdy reports grants from National Dairy Council, Novo Nordisk, Abbott Nutrition, Intarcia, Inc., and Metagenics, Inc., personal fees from AstraZeneca and Merck, and is a shareholder for Healthimation, LLC.

Human and Animal Rights and Informed Consent This article does not contain any studies with human or animal subjects performed by any of the authors.

Open Access This article is distributed under the terms of the Creative Commons Attribution 4.0 International License (http:// creativecommons.org/licenses/by/4.0/), which permits unrestricted use, distribution, and reproduction in any medium, provided you give appropriate credit to the original author(s) and the source, provide a link to the Creative Commons license, and indicate if changes were made.

\section{References}

Papers of particular interest, published recently, have been highlighted as:

- Of importance

•. Of major importance

1. Kjær IGH, Kolle E, Hansen BH, Anderssen SA, Torstveit MK. Obesity prevalence in Norwegian adults assessed by body mass index, waist circumference and fat mass percentage. Clinical Obesity. 2015;5(4):211-8. doi:10.1111/cob.12100.

2.• Flegal KM, Kruszon-Moran D, Carroll MD, Fryar CD, Ogden CL. Trends in obesity among adults in the United States, 2005 to 2014. JAMA. 2016;315(21):2284-91. doi:10.1001/jama.2016. 6458. This report utilizes data from the National Health and Nutrition Examination Survey (NHANES) to describe the alarming changes in obesity trends in the US.

3. Ghosh A, Charlton KE, Batterham MJ. Socioeconomic disadvantage and its implications for population health planning of obesity and overweight, using cross-sectional data from general practices from a regional catchment in Australia. BMJ Open. 2016;6(5): e010405. doi:10.1136/bmjopen-2015-010405.

4. Szadkowska A, Madej A, Ziolkowska K, Szymanska M, Jeziorny $\mathrm{K}$, Mianowska B, et al. Gender and age-dependent effect of type 1 diabetes on obesity and altered body composition in young adults. Annals of Agricultural and Environmental Medicine: AAEM. 2015;22(1):124-8. doi:10.5604/12321966.1141381.

5. Conway B, Miller RG, Costacou T, Fried L, Kelsey S, Evans RW, et al. Temporal patterns in overweight and obesity in type 1 diabetes. Diabet Med. 2010;27(4):398-404. doi:10.1111/j.1464-5491.2010. 02956.x.

6. Chillaron JJ, Benaiges D, Mane L, Pedro-Botet J, Flores Le-Roux JA. Obesity and type 1 diabetes mellitus management. Minerva Endocrinol. 2015;40(1):53-60.
7.• de Ferranti SD, de Boer IH, Fonseca V, Fox CS, Golden SH, Lavie $\mathrm{CJ}$, et al. Type 1 diabetes mellitus and cardiovascular disease: a scientific statement from the American Heart Association and American Diabetes Association. Diabetes Care. 2014;37(10): 2843-63. doi:10.2337/dc14-1720. This report focuses on the importance of cardiovascular disease in patients with T1D

8. Secrest AM, Becker DJ, Kelsey SF, LaPorte RE, Orchard TJ. Cause-specific mortality trends in a large population-based cohort with long-standing childhood-onset type 1 diabetes. Diabetes. 2010;59(12):3216-22. doi:10.2337/db10-0862.

9. Russell-Jones D, Khan R. Insulin-associated weight gain in diabetes - causes, effects and coping strategies. Diabetes Obes Metab. 2007;9(6):799-812. doi:10.1111/j.1463-1326.2006. 00686.x.

10. Valla V. Therapeutics of diabetes mellitus: focus on insulin analogues and insulin pumps. Exp Diabetes Res. 2010;2010:178372. doi: $10.1155 / 2010 / 178372$.

11. Jacob AN, Salinas K, Adams-Huet B, Raskin P. Potential causes of weight gain in type 1 diabetes mellitus. Diabetes Obes Metab. 2006;8(4):404-11. doi:10.1111/j.1463-1326.2005.00515.x.

12. Giuffrida FM, Bulcao C, Cobas RA, Negrato CA, Gomes MB, Dib SA. Double-diabetes in a real-world sample of 2711 individuals: associated with insulin treatment or part of the heterogeneity of type 1 diabetes? Diabetol Metab Syndr. 2016;8:28. doi:10.1186/s13098016-0143-7.

13. DCCTResearchGroup. Effect of intensive diabetes management on macrovascular events and risk factors in the Diabetes Control and Complications Trial. Am J Cardiol. 1995;75(14):894-903.

14. Misso ML, Egberts KJ, Page M, O'Connor D, Shaw J. Continuous subcutaneous insulin infusion (CSII) versus multiple insulin injections for type 1 diabetes mellitus. The Cochrane database of systematic reviews. 2010;1:CD005103. doi:10.1002/14651858. CD005103.pub2.

15. Williams KV, Erbey JR, Becker D, Orchard TJ. Improved glycemic control reduces the impact of weight gain on cardiovascular risk factors in type 1 diabetes. The Epidemiology of Diabetes Complications Study. Diabetes Care. 1999;22(7):1084-91.

16.• Schechter R, Reutrakul S. Management of severe insulin resistance in patients with type 1 diabetes. Current diabetes reports. 2015;15(10):1-12. doi:10.1007/s11892-015-0641-2. This review describes pharmacological therapy for patients with T1D and insulin resistance

17. Bush MA. Intensive diabetes therapy and body weight: focus on insulin detemir. Endocrinol Metab Clin N Am. 2007;36(Suppl 1): 33-44.

18. Timar R, Timar B, Degeratu D, Serafinceanu C, Oancea C. Metabolic syndrome, adiponectin and proinflammatory status in patients with type 1 diabetes mellitus. J Int Med Res. 2014;42(5): 1131-8. doi:10.1177/0300060514541829. This study investigates the prevalence of metabolic syndrome and evaluates various inflammatory markers in patients with T1D

19. Gomez-Ambrosi J, Catalan V, Ramirez B, Rodriguez A, Colina I, Silva C, et al. Plasma osteopontin levels and expression in adipose tissue are increased in obesity. J Clin Endocrinol Metab. 2007;92(9):3719-27. doi:10.1210/jc.2007-0349.

20. Barchetta I, Alessandri C, Bertoccini L, Cimini FA, Taverniti L, Di Franco M, et al. Increased circulating osteopontin levels in adult patients with type 1 diabetes mellitus and association with dysmetabolic profile. European Journal of Endocrinology/ European Federation of Endocrine Societies. 2016;174(2):18792. doi:10.1530/EJE-15-0791.

21. Colberg SR, Laan R, Dassau E, Kerr D. Physical activity and type 1 diabetes: time for a rewire? Journal of Diabetes Science and Technology. 2015;9(3):609-18. doi:10.1177/1932296814566231. 
22. Burr JF, Shephard RJ, Riddell MC. Physical activity in type 1 diabetes mellitus: assessing risks for physical activity clearance and prescription. Can Fam Physician. 2012;58(5):533-5.

23. Francescato MP, Stel G, Stenner E, Geat M. Prolonged exercise in type 1 diabetes: performance of a customizable algorithm to estimate the carbohydrate supplements to minimize glycemic imbalances. PLoS One. 2015;10(4):e0125220. doi:10.1371/journal. pone. 0125220

24. ADA. Foundations of care and comprehensive medical evaluation. Sec. 3. In standards of medical care in diabetes - 2016 . Diabetes Care. 2016;39(Suppl 1):S23-35. doi:10.2337/dc16S006.

25. Shai I, Schwarzfuchs D, Henkin Y, Shahar DR, Witkow S, Greenberg I, et al. Weight loss with a low-carbohydrate, Mediterranean, or low-fat diet. N Engl J Med. 2008;359(3):229 41. doi:10.1056/NEJMoa0708681.

26. Barnard ND, Cohen J, Jenkins DJ, Turner-McGrievy G, Gloede L, Green A, et al. A low-fat vegan diet and a conventional diabetes diet in the treatment of type 2 diabetes: a randomized, controlled, 74-wk clinical trial. Am J Clin Nutr. 2009;89(5):1588S-96S. doi: 10.3945/ajen.2009.26736H.

27. Shirani F, Salehi-Abargouei A, Azadbakht L. Effects of Dietary Approaches to Stop Hypertension (DASH) diet on some risk for developing type 2 diabetes: a systematic review and meta-analysis on controlled clinical trials. Nutrition. 2013;29(7-8):939-47. doi: 10.1016/j.nut.2012.12.021

28. Lee YM, Kim SA, Lee IK, Kim JG, Park KG, Jeong JY, et al. Effect of a brown rice based vegan diet and conventional diabetic diet on glycemic control of patients with type 2 diabetes: a 12 week randomized clinical trial. PLoS One. 2016;11(6):e0155918. doi:10.1371/journal.pone.0155918.

29. Yokoyama Y, Barnard ND, Levin SM, Watanabe M. Vegetarian diets and glycemic control in diabetes: a systematic review and meta-analysis. Cardiovasc Diagn Ther. 2014;4(5):373-82. doi:10. 3978/j.issn.2223-3652.2014.10.04.

30. Liese AD, Nichols M, Sun X, D'Agostino RB Jr, Haffner SM. Adherence to the DASH diet is inversely associated with incidence of type 2 diabetes: the Insulin Resistance Atherosclerosis Study. Diabetes Care. 2009;32(8):1434-6. doi:10.2337/dc09-0228.

31. Evert AB, Boucher JL, Cypress M, Dunbar SA, Franz MJ, MayerDavis EJ, et al. Nutrition therapy recommendations for the management of adults with diabetes. Diabetes Care. 2014;37(Supplement 1):S120-S43. This is a position statement by the American Diabetes Association (ADA) outlining its recommendations for nutrition therapy in adults with diabetes

32. Burger KN, Beulens JW, van der Schouw YT, Sluijs I, Spijkerman AM, Sluik D, et al. Dietary fiber, carbohydrate quality and quantity, and mortality risk of individuals with diabetes mellitus. PLoS One. 2012;7(8):e43127. doi:10.1371/journal.pone.0043127.

33. Parillo M, Annuzzi G, Rivellese AA, Bozzetto L, Alessandrini R, Riccardi G, et al. Effects of meals with different glycaemic index on postprandial blood glucose response in patients with type 1 diabetes treated with continuous subcutaneous insulin infusion. Diabetic medicine : a journal of the British Diabetic Association. 2011;28(2):227-9. doi:10.1111/j.1464-5491.2010.03176.x.

34. Wheeler ML, Dunbar SA, Jaacks LM, Karmally W, Mayer-Davis EJ, Wylie-Rosett J, et al. Macronutrients, food groups, and eating patterns in the management of diabetes: a systematic review of the literature, 2010. Diabetes Care. 2012;35(2):434 45. doi:10.2337/ dc11-2216.

35. Franz MJ, Boucher JL, Evert AB. Evidence-based diabetes nutrition therapy recommendations are effective: the key is individualization. Diabetes, Metabolic Syndrome and Obesity: Targets and Therapy. 2014;7:65-72. doi:10.2147/dmso.s45140.

36. Estruch R, Ros E, Salas-Salvado J, Covas MI, Corella D, Aros F, et al. Primary prevention of cardiovascular disease with a
Mediterranean diet. N Engl J Med. 2013;368(14):1279-90. doi: 10.1056/NEJMoa1200303.

37. Miller CT, Fraser SF, Levinger I, Straznicky NE, Dixon JB, Reynolds J, et al. The effects of exercise training in addition to energy restriction on functional capacities and body composition in obese adults during weight loss: a systematic review. PLoS One. 2013;8(11):e81692. doi:10.1371/journal.pone.0081692.

38. Washburn RA, Szabo AN, Lambourne K, Willis EA, Ptomey LT, Honas JJ, et al. Does the method of weight loss effect long-term changes in weight, body composition or chronic disease risk factors in overweight or obese adults? A systematic review. PLoS One. 2014;9(10):e109849. doi:10.1371/journal.pone.0109849.

39. Chimen M, Kennedy A, Nirantharakumar K, Pang TT, Andrews $\mathrm{R}$, Narendran P. What are the health benefits of physical activity in type 1 diabetes mellitus? A literature review. Diabetologia. 2012;55(3):542-51. doi:10.1007/s00125-011-2403-2.

40. Fuchsjäger-Mayrl G, Pleiner J, Wiesinger GF, Sieder AE, Quittan M, Nuhr MJ, et al. Exercise training improves vascular endothelial function in patients with type 1 diabetes. Diabetes Care. 2002;25(10):1795-801. doi:10.2337/diacare.25.10.1795.

41. Hawley JA. Exercise as a therapeutic intervention for the prevention and treatment of insulin resistance. Diabetes Metab Res Rev. 2004;20(5):383-93. doi:10.1002/dmrr.505.

42. Swift DL, Johannsen NM, Lavie CJ, Earnest CP, Church TS. The role of exercise and physical activity in weight loss and maintenance. Prog Cardiovasc Dis. 2014;56(4):441-7. doi:10.1016/j. pcad.2013.09.012.

43. Ismail I, Keating SE, Baker MK, Johnson NA. A systematic review and meta-analysis of the effect of aerobic vs. resistance exercise training on visceral fat. Obesity Reviews: an Official Journal of the International Association for the Study of Obesity. 2012;13(1):68-91. doi:10.1111/j.1467-789X.2011.00931.x.

44. Hunter GR, Byrne NM, Sirikul B, Fernandez JR, Zuckerman PA, Darnell BE, et al. Resistance training conserves fat-free mass and resting energy expenditure following weight loss. Obesity (Silver Spring). 2008;16(5):1045-51. doi:10.1038/oby.2008.38.

45. Leenders M, Verdijk LB, van der Hoeven L, Adam JJ, van Kranenburg J, Nilwik R, et al. Patients with type 2 diabetes show a greater decline in muscle mass, muscle strength, and functional capacity with aging. J Am Med Dir Assoc. 2013;14(8):585-92. doi:10.1016/j.jamda.2013.02.006.

46. Heydari M, Freund J, Boutcher SH. The effect of high-intensity intermittent exercise on body composition of overweight young males. J Obes. 2012;2012:480467. doi:10.1155/2012/480467.

47. Madsen SM, Thorup AC, Overgaard K, Jeppesen PB. High intensity interval training improves glycaemic control and pancreatic $\beta$ cell function of type 2 diabetes patients. PLoS One. 2015;10(8): e0133286. doi:10.1371/journal.pone.0133286.

48. Trapp E, Chisholm D, Freund J, Boutcher S. The effects of highintensity intermittent exercise training on fat loss and fasting insulin levels of young women. Int J Obes. 2008;32(4):684-91.

49. Keating SE, Machan EA, O'Connor HT, Gerofi JA, Sainsbury A, Caterson ID, et al. Continuous exercise but not high intensity interval training improves fat distribution in overweight adults. $\mathrm{J}$ Obes. 2014;2014:834865. doi:10.1155/2014/834865.

50. Rabasa-Lhoret R, Bourque J, Ducros F, Chiasson JL. Guidelines for premeal insulin dose reduction for postprandial exercise of different intensities and durations in type 1 diabetic subjects treated intensively with a basal-bolus insulin regimen (ultralentelispro). Diabetes Care. 2001;24(4):625-30.

51.• Riddell MC, Gallen IW, Smart CE, Taplin CE, Adolfsson P, Lumb AN, et al. Exercise management in type 1 diabetes: a consensus statement. The Lancet Diabetes \& Endocrinology. 2017;5(5):377-90. doi: 10.1016/s2213-8587(17)30014-1. This review provides new recommendations for exercise management in patients with T1D 
52. Mitri J, Hamdy O. Diabetes medications and body weight. Expert Opin Drug Saf. 2009;8(5):573-84. doi:10.1517/ 14740330903081725.

53. Dornhorst A, Luddeke HJ, Sreenan S, Kozlovski P, Hansen JB, Looij $\mathrm{BJ}$, et al. Insulin detemir improves glycaemic control without weight gain in insulin-naive patients with type 2 diabetes: subgroup analysis from the PREDICTIVE study. Int J Clin Pract. 2008;62(4):659-65. doi:10.1111/j.1742-1241.2008.01715.x.

54. Yki-Jarvinen H, Kauppila M, Kujansuu E, Lahti J, Marjanen T, Niskanen L, et al. Comparison of insulin regimens in patients with non-insulin-dependent diabetes mellitus. N Engl J Med. 1992;327(20):1426-33. doi:10.1056/nejm199211123272005.

55. Heller S, Buse J, Fisher M, Garg S, Marre M, Merker L, et al. Insulin degludec, an ultra-longacting basal insulin, versus insulin glargine in basal-bolus treatment with mealtime insulin aspart in type 1 diabetes (BEGIN Basal-Bolus Type 1): a phase 3, randomised, open-label, treat-to-target non-inferiority trial. Lancet (London, England). 2012;379(9825):1489-97. doi:10. 1016/s0140-6736(12)60204-9.

56. Mathieu C, Hollander P, Miranda-Palma B, Cooper J, Franek E, Russell-Jones D, et al. Efficacy and safety of insulin degludec in a flexible dosing regimen vs insulin glargine in patients with type 1 diabetes (BEGIN: Flex T1): a 26-week randomized, treat-to-target trial with a 26-week extension. J Clin Endocrinol Metab. 2013;98(3):1154-62. doi:10.1210/jc.2012-3249.

57. Home PD, Bergenstal RM, Bolli GB, Ziemen M, Rojeski M, Espinasse M, et al. New insulin glargine 300 units $/ \mathrm{mL}$ versus glargine 100 units $/ \mathrm{mL}$ in people with type 1 diabetes: a randomized, phase 3a, open-label clinical trial (EDITION 4). Diabetes Care. 2015;38(12):2217-25. doi:10.2337/dc15-0249.

58. Garg SK, Rosenstock J, Ways K. Optimized basal-bolus insulin regimens in type 1 diabetes: insulin glulisine versus regular human insulin in combination with basal insulin glargine. Endocrine Practice: Official Journal of the American College of Endocrinology and the American Association of Clinical Endocrinologists. 2005;11(1):11-7. doi:10.4158/ep.11.1.11.

59. Viollet B, Guigas B, Sanz Garcia N, Leclerc J, Foretz M, Andreelli F. Cellular and molecular mechanisms of metformin: an overview. Clinical Science (London, England: 1979). 2012;122(6):253-70. doi:10.1042/cs20110386.

60. Burchardt P, Zawada A, Tabaczewski P, Naskret D, Kaczmarek J, Marcinkaniec J, et al. Metformin added to intensive insulin therapy reduces plasma levels of glycated but not oxidized lowdensity lipoprotein in young patients with type 1 diabetes and obesity in comparison with insulin alone: a pilot study. Polskie Archiwum Medycyny Wewnetrznej. 2013;123(10):526-32.

61.• Petrie JR, Chaturvedi N, Ford I, Brouwers M, Greenlaw N, Tillin $\mathrm{T}$, et al. Cardiovascular and metabolic effects of metformin in patients with type 1 diabetes (REMOVAL): a double-blind, randomised, placebo-controlled trial. The Lancet Diabetes \& endocrinology. 2017; doi:10.1016/s2213-8587(17)30194-8. This study describes long-term outcomes of metformin use in adults with T1D

62. Holst JJ. Incretin hormones and the satiation signal. International Journal of Obesity (2005). 2013;37(9):1161-8. doi:10.1038/ijo. 2012.208

63. Dejgaard TF, Frandsen CS, Holst JJ, Madsbad S. Liraglutide for treating type 1 diabetes. Expert Opin Biol Ther. 2016;16(4):579_ 90. doi:10.1517/14712598.2016.1160050.

64.• Janzen KM, Steuber TD, Nisly SA. GLP-1 agonists in type 1 diabetes mellitus. Ann Pharmacother. 2016;50(8):656-65. doi: $10.1177 / 1060028016651279$. This article reviews all trials to date that used GLP-1 analogs in patients with T1D

65. Varanasi A, Bellini N, RawalD, Vora M, Makdissi A, Dhindsa S, etal. Liraglutide as additional treatment for type 1 diabetes. European
Journal of Endocrinology/European Federation of Endocrine Societies. 2011;165(1):77-84. doi:10.1530/eje-11-0330.

66. Wing RR, Bolin P, Brancati FL, Bray GA, Clark JM, Coday M, et al. Cardiovascular effects of intensive lifestyle intervention in type 2 diabetes. N Engl J Med. 2013;369(2):145-54. doi:10.1056/ NEJMoa1212914.

67. Kielgast U, Krarup T, Holst JJ, Madsbad S. Four weeks of treatment with liraglutide reduces insulin dose without loss of glycemic control in type 1 diabetic patients with and without residual beta-cell function. Diabetes Care. 2011;34(7):1463-8. doi:10.2337/dc11-0096.

68. Ghazi T, Rink L, Sherr JL, Herold KC. Acute metabolic effects of exenatide in patients with type 1 diabetes with and without residual insulin to oral and intravenous glucose challenges. Diabetes Care. 2014;37(1):210-6. doi:10.2337/dc13-1169.

69. Traina AN, Lull ME, Hui AC, Zahorian TM, Lyons-Patterson J. Once-weekly exenatide as adjunct treatment of type 1 diabetes mellitus in patients receiving continuous subcutaneous insulin infusion therapy. Can J Diabetes. 2014;38(4):269-72. doi:10.1016/j. jcjd.2013.10.006.

70. Hari Kumar KV, Shaikh A, Prusty P. Addition of exenatide or sitagliptin to insulin in new onset type 1 diabetes: a randomized, open label study. Diabetes Res Clin Pract. 2013;100(2):e55-8. doi:10.1016/j.diabres.2013.01.020.

71. Thule PM. Mechanisms of current therapies for diabetes mellitus type 2. Adv Physiol Educ. 2012;36(4):275-83. doi:10.1152/ advan.00094.2012.

72. Herrmann K, Brunell SC, Li Y, Zhou M, Maggs DG. Impact of disease duration on the effects of pramlintide in type 1 diabetes: a post hoc analysis of three clinical trials. Adv Ther. 2016;33(5): 848-61. doi:10.1007/s12325-016-0326-5. This study describes the effects of pramlintide treatment in patients with T1D across a wide range of disease duration

73. Ferrannini E. Sodium-glucose co-transporters and their inhibition: clinical physiology. Cell Metab. 2017; doi:10.1016/j.cmet.2017.04.011.

74. Abdul-Ghani MA, Norton L, DeFronzo RA. Renal sodiumglucose cotransporter inhibition in the management of type 2 diabetes mellitus. American Journal of Physiology Renal physiology. 2015;309(11):F889-900. doi:10.1152/ajprenal.00267.2015.

75. Heerspink HJ, Perkins BA, Fitchett DH, Husain M, Cherney DZ. Sodium glucose cotransporter 2 inhibitors in the treatment of diabetes mellitus: cardiovascular and kidney effects, potential mechanisms, and clinical applications. Circulation. 2016;134(10):75272. doi:10.1161/circulationaha.116.021887.

76. Neal B, Perkovic V, Mahaffey KW, de Zeeuw D, Fulcher G, Erondu N, et al. Canagliflozin and cardiovascular and renal events in type 2 diabetes. N Engl J Med. doi:10.1056/NEJMoa1611925.

77. Perkins BA, Cherney DZ, Partridge H, Soleymanlou N, Tschirhart $\mathrm{H}$, Zinman B, et al. Sodium-glucose cotransporter 2 inhibition and glycemic control in type 1 diabetes: results of an 8-week openlabel proof-of-concept trial. Diabetes Care. 2014;37(5):1480-3. doi: $10.2337 / \mathrm{dc} 13-2338$

78. Henry RR, Rosenstock J, Edelman S, Mudaliar S, Chalamandaris AG, Kasichayanula S, et al. Exploring the potential of the SGLT2 inhibitor dapagliflozin in type 1 diabetes: a randomized, doubleblind, placebo-controlled pilot study. Diabetes Care. 2015;38(3): 412-9. doi:10.2337/dc13-2955.

79. Sands AT, Zambrowicz BP, Rosenstock J, Lapuerta P, Bode BW, Garg SK, et al. Sotagliflozin, a dual SGLT1 and SGLT2 inhibitor, as adjunct therapy to insulin in type 1 diabetes. Diabetes Care. 2015;38(7):1181-8. doi:10.2337/dc14-2806. This study reports significant body weight reduction and improvement in glycemic control among patients with T1D treated with the SGLT2 inhibitor sotagliflozin

80. Daneschvar HL, Aronson MD, Smetana GW. FDA-approved antiobesity drugs in the United States. Am J Med. 2016;129(8): 879.e1-6. doi:10.1016/j.amjmed.2016.02.009. 
81. O'Neil PM, Smith SR, Weissman NJ, Fidler MC, Sanchez M, Zhang J, et al. Randomized placebo-controlled clinical trial of lorcaserin for weight loss in type 2 diabetes mellitus: the BLOOM-DM study. Obesity (Silver Spring). 2012;20(7):142636. doi:10.1038/oby.2012.66.

82. Garvey WT, Ryan DH, Look M, Gadde KM, Allison DB, Peterson CA, et al. Two-year sustained weight loss and metabolic benefits with controlled-release phentermine/topiramate in obese and overweight adults (SEQUEL): a randomized, placebo-controlled, phase 3 extension study. Am J Clin Nutr. 2012;95(2): 297-308. doi:10.3945/ajen.111.024927.

83. Hollander P, Gupta AK, Plodkowski R, Greenway F, Bays H, Burns $\mathrm{C}$, et al. Effects of naltrexone sustained-release/bupropion sustainedrelease combination therapy on body weight and glycemic parameters in overweight and obese patients with type 2 diabetes. Diabetes Care. 2013;36(12):4022-9. doi:10.2337/dc13-0234.

84. Vasas P, Por F. Surgical options for reducing body weight. Orv Hetil. 2014;155(25):971-7. doi:10.1556/oh.2014.29844.

85. Gill RS, Majumdar SR, Rueda-Clausen CF, Apte S, Birch DW, Karmali S, et al. Comparative effectiveness and safety of gastric bypass, sleeve gastrectomy and adjustable gastric banding in a population-based bariatric program: prospective cohort study. Canadian journal of surgery Journal canadien de chirurgie. 2016;59(4):13315. doi:10.1503/cjs.013315.

86. Praveenraj P, Gomes RM, Kumar S, Perumal S, Senthilnathan P, Parthasarathi R, et al. Comparison of weight loss outcomes 1 year after sleeve gastrectomy and Roux-en-Y gastric bypass in patients aged above 50 years. Journal of minimal access surgery. 2016;12(3):220-5. doi:10.4103/0972-9941.183481.

87. Adams TD, Arterburn DE, Nathan DM, Eckel RH. Clinical outcomes of metabolic surgery: microvascular and macrovascular complications. Diabetes Care. 2016;39(6):912-23. doi:10.2337/ dc16-0157.

88. Lee SK, Heo Y, Park JM, Kim YJ, Kim SM, Park do J, et al. Rouxen-Y gastric bypass vs. sleeve gastrectomy vs. gastric banding: the first multicenter retrospective comparative cohort study in obese Korean patients. Yonsei Med J. 2016;57(4):956-62. doi:10.3349/ ymj.2016.57.4.956.

89. Grubnik VV, Ospanov OB, Namaeva KA, Medvedev OV, Kresyun MS. Randomized controlled trial comparing laparoscopic greater curvature plication versus laparoscopic sleeve gastrectomy. Surg Endosc. 2016;30(6):2186-91. doi:10.1007/s00464015-4373-9.

90. Lager CJ, Esfandiari NH, Subauste AR, Kraftson AT, Brown MB, Cassidy RB, et al. Roux-en-Y gastric bypass vs. sleeve gastrectomy: balancing the risks of surgery with the benefits of weight loss. Obes Surg. 2017;27(1):154-61. doi:10.1007/s11695-016-2265-2.

91. Sabbagh C, Verhaeghe P, Dhahri A, Brehant O, Fuks D, Badaoui $\mathrm{R}$, et al. Two-year results on morbidity, weight loss and quality of life of sleeve gastrectomy as first procedure, sleeve gastrectomy after failure of gastric banding and gastric banding. Obes Surg. 2010;20(6):679-84. doi:10.1007/s11695-009-0007-4.

92. Purnell JQ, Selzer F, Wahed AS, Pender J, Pories W, Pomp A, et al. Type 2 diabetes remission rates after laparoscopic gastric bypass and gastric banding: results of the longitudinal assessment of bariatric surgery study. Diabetes Care. 2016;39(7):1101-7. doi: 10.2337/dc15-2138.

93.• Kirwan JP, Aminian A, Kashyap SR, Burguera B, Brethauer SA, Schauer PR. Bariatric surgery in obese patients with type 1 diabetes. Diabetes Care. 2016;39(6):941-8. doi:10.2337/dc15-2732. A review of bariatric surgery outcomes conducted in patients with T1D and obesity
94. Abdeen G, le Roux CW. Mechanism underlying the weight loss and complications of Roux-en-Y gastric bypass. Review Obes Surg. 2016;26(2):410-21. doi:10.1007/s11695-015-1945-7.

95. Holst JJ. Postprandial insulin secretion after gastric bypass surgery: the role of glucagon-like peptide 1. Diabetes. 2011;60(9): 2203-5. doi:10.2337/db11-0798.

96. Holst JJ, Madsbad S. Mechanisms of surgical control of type 2 diabetes: GLP-1 is key factor. Surgery for Obesity and Related Diseases: Official Journal of the American Society for Bariatric Surgery. 2016;12(6):1236-42. doi:10.1016/j.soard.2016.02.033.

97. Kratz M, Hagman DK, Kuzma JN, Foster-Schubert KE, Chan CP, Stewart S, et al. Improvements in glycemic control after gastric bypass occur despite persistent adipose tissue inflammation. Obesity (Silver Spring). 2016;24(7):1438-45. doi:10.1002/oby.21524.

98. Smith BR, Hinojosa MW, Reavis KM, Nguyen NT. Remission of diabetes after laparoscopic gastric bypass. Am Surg. 2008;74(10): 948-52.

99. Dixon JB, Chuang LM, Chong K, Chen SC, Lambert GW, Straznicky NE, et al. Predicting the glycemic response to gastric bypass surgery in patients with type 2 diabetes. Diabetes Care. 2013;36(1):20-6. doi:10.2337/dc12-0779.

100. Hara M, Fowler JL, Bell GI, Philipson LH. Resting beta-cells - a functional reserve? Diabetes \& Metabolism. 2016;42(3):157-61. doi:10.1016/j.diabet.2016.01.001.

101. Celio AC, Wu Q, Kasten KR, Manwaring ML, Pories WJ, Spaniolas K. Comparative effectiveness of Roux-en-Y gastric bypass and sleeve gastrectomy in super obese patients. Surg Endosc. 2017;31(1):317-23. doi:10.1007/s00464-016-4974-y.

102. Nannipieri M, Belligoli A, Guarino D, Busetto L, Moriconi D, Fabris R, et al. Risk factors for spontaneously self-reported postprandial hypoglycemia after bariatric surgery. J Clin Endocrinol Metab. 2016;101(10):3600-7. doi:10.1210/jc.2016-1143.

103. Felsenreich DM, Langer FB, Kefurt R, Panhofer P, Schermann M, Beckerhinn $P$, et al. Weight loss, weight regain, and conversions to Roux-en-Y gastric bypass: 10-year results of laparoscopic sleeve gastrectomy. Surgery for Obesity and Related Diseases: Official Journal of the American Society for Bariatric Surgery. 2016;12(9): 1655-62. doi:10.1016/j.soard.2016.02.021.

104. Lalor PF, TuckerON, Szomstein S, Rosenthal RJ. Complications after laparoscopic sleeve gastrectomy. Surgery for Obesity and Related Diseases: Official Journal of the American Society for Bariatric Surgery. 2008;4(1):33-8. doi:10.1016/j.soard.2007.08.015.

105. Yildiz B, Katar K, Hamamci O. Efficacy of laparoscopic sleeve gastrectomy for the treatment of obesity in a non-western society. Eating and Weight Disorders: EWD. 2016;21(4):695-9. doi:10. 1007/s40519-016-0287-3.

106. Shah N, Greenberg JA, Leverson G, Statz AK, Jolles SA, Funk LM. Weight loss after bariatric surgery: a propensity score analysis. J Surg Res. 2016;202(2):449-54. doi:10.1016/j.jss.2016.01.041.

107. Faucher P, Poitou C, Carette C, Tezenas du Montcel S, Barsamian $\mathrm{C}$, Touati E, et al. Bariatric surgery in obese patients with type 1 diabetes: effects on weight loss and metabolic control. Obes Surg. 2016;26(10):2370-8. doi:10.1007/s11695-016-2106-3.

108. Lannoo M, Dillemans B, Van Nieuwenhove Y, Fieuws S, Mathieu $\mathrm{C}$, Gillard P, et al. Bariatric surgery induces weight loss but does not improve glycemic control in patients with type 1 diabetes. Diabetes Care. 2014;37(8):e173-4. doi:10.2337/dc14-0583.

109. Maraka S, Kudva YC, Kellogg TA, Collazo-Clavell ML, Mundi MS. Bariatric surgery and diabetes: implications of type 1 versus insulin-requiring type 2. Obesity (Silver Spring). 2015;23(3):5527. doi:10.1002/oby.20992. 